J. Lake Sci.(湖泊科学), 2020, 32(2): 428-439

DOI 10. 18307/2020. 0205

(C) 2020 by Journal of Lake Sciences

\title{
高邮湖、南四湖和东平湖有色可溶性有机物来源组成特征”
}

\author{
张柳青 $^{1,2}$, 杨 艳 ${ }^{2}$, 李元鹏 ${ }^{1}$, 石 玉 $^{1}$, 周 雷 $^{1,3}$, 周永强 ${ }^{1,3 * *}$, 张运林 $^{1,3}$ \\ (1: 中国科学院南京地理与湖泊研究所湖泊与环境国家重点实验室, 南京 210008) \\ (2: 西华师范大学环境科学与工程学院, 南充 637000) \\ (3: 中国科学院大学,北京 100049)
}

\begin{abstract}
摘 要: 高邮湖、南四湖和东平湖作为南水北调东线枢纽湖泊,其水质状况对保障调水安全起到关键性作用. 本文运用三 维苂光光谱一平行因子分析法 (EEMs-PARAFAC) 分析了 3 个湖泊在不同水文情景下有色可溶性有机物 (CDOM) 吸收、苂 光光谱特征以及苂光组分与主要水质参数的相关性, 以探究 3 个湖泊 CDOM 来源组成特征. 结果表明, 平行因子分析法 解析 CDOM 三维苂光图谱, 得到陆源类腐殖质 $\mathrm{C} 1$ 、类色氨酸 $\mathrm{C} 2$ 和类酪氨酸 $\mathrm{C} 3$. 不同水文情景对高邮湖 CDOM 来源与结 构组成影响较明显, 丰水期其类腐殖质苂光强度显著大于枯水期 $(t$-test, $P<0.01)$, 并且与 $a(254)$ 呈正相关 $\left(R^{2}=0.85\right.$, $P<0.01)$, 表明类腐殖质是 CDOM 主要部分, 该苂光组分贡献率可达 $50 \%\left[F_{\text {max }} \mathrm{C} 1 /\left(F_{\text {max }} \mathrm{C} 1+F_{\text {max }} \mathrm{C} 2+F_{\text {max }} \mathrm{C} 3\right) \times 100 \%\right]$, 高邮湖受到入湖河流来水的影响较大, 丰水期人湖口附近苂光强度明显高于其他水域. 东平湖和南四湖 CDOM 来源组成 特征相似, 丰水期东平湖和南四湖组分 C2 和 C 3 显著低于枯水期 ( $t$-test, $P<0.01$ ), 两湖泊枯水期工农业等人为污染源影 响较大. 相关性分析表明高邮湖中类腐殖质荧光特征在一定程度是能反演 DOC 浓度, 并且类腐殖质的输人会增加湖泊总 磷、总氮和叶绿素 $\mathrm{a}$ 浓度. 而东平湖和南四湖 CDOM 苂光特征与主要水质参数的相关性较差, 这与高邮湖水体存在较大 差异.
\end{abstract}

关键词 : 南水北调; 高邮湖;南四湖; 东平湖;有色可溶性有机物;平行因子分析

\section{Sources and optical dynamics of chromophoric dissolved organic matter in Lake Gaoyou, Nansi, and Dongping*}

ZHANG Liuqing ${ }^{1,2}$, YANG Yan $^{2}$, LI Yuanpeng ${ }^{1}$, SHI Yu ${ }^{1}$, ZHOU Lei ${ }^{1,3}$, ZHOU Yongqiang ${ }^{1,3 * *} \&$ ZHANG Yunlin ${ }^{1,3}$

(1: State Key Laboratory of Lake Science and Environment, Nanjing Institute of Geography and Limnology, Chinese Academy of Sciences, Nanjing 210008, P.R. China)

(2: College of Environment Science and Engineering, China West Normal University, Nanchong 637000, P.R.China)

(3: University of Chinese Academy of Sciences, Beijing 100049, P.R.China)

\footnotetext{
Abstract: Lake Gaoyou, Nansi, and Dongping are key connecting points on the east line of the South-to-North Water Diversion Project and play vital roles in the safety of water transfer. In this study, three-dimensional fluorescence spectroscopy coupled with parallel factor analysis (EEMs-PARAFAC) was used to analyze the optical characteristics of CDOM and the relationships between fluorescence components and water quality parameters in the three lakes in different hydrological seasons, and to unravel the sources and optical composition characteristics of CDOM. Three fluorescent components were obtained using parallel factor analysis (PARAFAC), including a terrestrial humic-like C1, a tryptophan-like C2 and a tyrosine-like C3. Upstream inflowing discharge have notable effects on the source and optical composition of CDOM in Lake Gaoyou with fluorescence intensity $\left(F_{\max }\right)$ of C1 in the flood season is significantly higher than in the dry season $(t$-test, $P<0.01)$, and C1 is positively correlated with $a(254)\left(R^{2}=\right.$

* 2019-03-11 收稿; 2019-07-06 收修改稿.

国家自然科学基金项目 (41807362, 41621002)、江苏省自然科学基金项目 (BK20181104)、中国科学院前沿科学重 点研究计划项目 (QYZDB-SSW-DQC016) 和中国科学院南京地理与湖泊研究所启动基金项目 (NIGLAS2017QD08) 联合资助.

** 通信作者; E-mail:yqzhou@ niglas.ac.cn.
} 
0.85, $P<0.01)$, indicating that terrestrial humic-like substances contributed primarily to the DOM pool in the lake. The contribution rate of $\mathrm{C} 1$ can reach $50 \%\left[F_{\max } \mathrm{C} 1 /\left(F_{\max } \mathrm{C} 1+F_{\max } \mathrm{C} 2+F_{\max } \mathrm{C} 3\right) \times 100 \%\right]$. Lake Gaoyou is greatly affected by the inflow water. Lake Dongping and Lake Nansi share similar source and optical composition of CDOM. The $F_{\max }$ mean of C2 and C3 in Lake Dongping and Lake Nansi were significantly lower in the flood season than in the dry season $(t$-test, $P<0.01)$, indicating the two lakes have a higher autochthonous CDOM contribution during the dry season. Humic-like C1 in Lake Gaoyou can be used to trace the dynamics of dissolved organic carbon concentration, and the accumulation of humic-like substances may increase the concentration of total phosphorus, totoal nitrogen, and chlorophyll- $a$ in the lake. However, the correlations between $\mathrm{C} 1$ and the main water quality parameters including humic-like C1 were poor in Lake Dongping and Lake Nansi, showing different CDOM optical characteristics from that of Lake Gaoyou.

Keywords: The South-to-North Water Diversion Project; Lake Gaoyou; Lake Nansi; Lake Dongping; chromophoric dissolved organic matter (CDOM); parallel factor analysis (PARAFAC)

南水北调东线南起扬州附近长江取水口,途径高邮湖、南四湖及东平湖等湖泊,将长江及沿线枢纽湖泊 水源输移到京津冀及山东等地, 上述 3 个湖泊在保障调水工程顺利开展中起到了不可忽视的重要作用,湖 泊的水质状况也是决定东线调水工程安全的关键 ${ }^{[1]}$. 研究发现大规模长途的调水也会改变调蓄湖泊的水环 境以及原有生态结构, 影响湖泊碳、氮、磷等生源物质的地球化学循环过程 ${ }^{[2]}$. 近年来, 由于经济发展和人口 增多, 导致东线调蓄湖泊及其周边河流部分水质发生恶化, 对受水区饮用水安全产生威胁 ${ }^{[3-5]}$. 东线工程大 部分的输水渠道是利用现有河道或湖泊, 为缺水城市提供生活用水、工业用水、环境用水等, 因此有必要对 工程沿线河道、湖泊的水质变化进行研究 ${ }^{[6-7]}$.

溶解性有机物质 ( dissolved organic matter,DOM) 广泛存在于自然水体中,其来源复杂,种类繁多,过量的 DOM 会致使水体酸臭刺鼻, 并且在水处理过程中通常能释放大量致癌物质, 既污染处理设备, 又会严重威胁 人类健康 ${ }^{[8]}$. 水体有色可溶有机物质 ( chromophoric DOM, CDOM) 是 DOM 中能强烈吸收紫外和可见光的部 分, 因而通过其吸收光谱能在一定程度上揭示 DOM 结构组成特征. 另外还有一部分物质能在短波激发下发 出长于激发波长的苂光, 这部分物质即为发苂光溶解性有机物 ( fluorescent DOM, FDOM $)^{[9]}$. 近年来已有多 位相关领域的研究者利用 CDOM 的光学特性及遥感反演等技术手段监测有机污染物浓度、来源及组成变 化, 相关研究主要针对富营养湖泊、海洋及河口等水域 ${ }^{[10-11]}$. 许多研究者在运用三维荧光结合平行因子分析 法 (EEMs-PARAFAC) 对 CDOM 进行半定量和定性的研究领域中有所成果. Shang 等 ${ }^{[12]}$ 强调了 CDOM 对研 究水体 DOM 输人的重要性, 并且加强了营养状态指数与 CDOM 来源组成特征之间的联系, 有助于建立一种 新的水库营养状态监测模式. $\mathrm{Hu}$ 等 ${ }^{[13]}$ 应用平行因子分析法对洪泽湖 CDOM 来源与组成特征进行分析, 揭 示了其水质状况及其影响因素. Coch 等 ${ }^{[14]}$ 通过研究 CDOM 光学特性来实现对北极河流的 DOM 的反演.

本研究对高邮湖、南四湖和东平湖在不同水文情境下 CDOM 的时空分布特征进行分析, 探讨了高邮湖、 南四湖和东平湖 CDOM 来源和组成特征, 丰富了南水北调东线枢纽湖泊水质的研究资料, 以期为进一步保 障南水北调东线调水安全和制定管理方案提供参考依据.

\section{1 材料与方法}

\section{1 样品采集与处理}

如图 1 所示, 在高邮湖、南四湖和东平湖分别布设 7 个 ( 7 个样点 $\times 2$ 次观测)、 15 个 ( 15 个样点 $\times 2$ 次观测) 及 6 个 $(6$ 个样点 $\times 2$ 次观测 $)$ 表层 $(0.5 \mathrm{~m})$ 水样采样点, 于 2018 年 4 、 7 月进行野外样品采集. 采集好的样品用 酸洗过的聚氯乙烯瓶避光冷藏保存并及时送回实验室. 先使用高温灼烧过 $\left(450^{\circ} \mathrm{C}\right.$ 烧 $\left.4 \mathrm{~h}\right)$ 的 $0.7 \mu \mathrm{m}$ 的 Whatman $\mathrm{GF} / \mathrm{F}$ 玻璃纤维滤膜过滤, 所得水样再通过 $0.22 \mu \mathrm{m}$ Millipore 滤膜过滤, 滤后水样装人棕色玻璃瓶, 并于 $4^{\circ} \mathrm{C}$ 恒 温冷藏保存, 在 5 天内完成所有指标的监测分析. 通过 $0.7 \mu \mathrm{m}$ 滤膜的水样用于测定溶解性有机碳 ( dissolved organic carbon, DOC) 浓度; 通过 $0.22 \mu \mathrm{m}$ 滤膜的水样用于测定 CDOM 吸收光谱和三维苂光光谱.

\section{2 水文数据}

本研究水文数据资料来自水利部淮河水利委员会 (http://www.hrc.gov.cn/) 和黄河水利委员会 (http:// www.yrcc.gov.cn/), 包括 2018 年逐月淮河流域降雨量和 2018 年逐月东平湖蓄水量. 

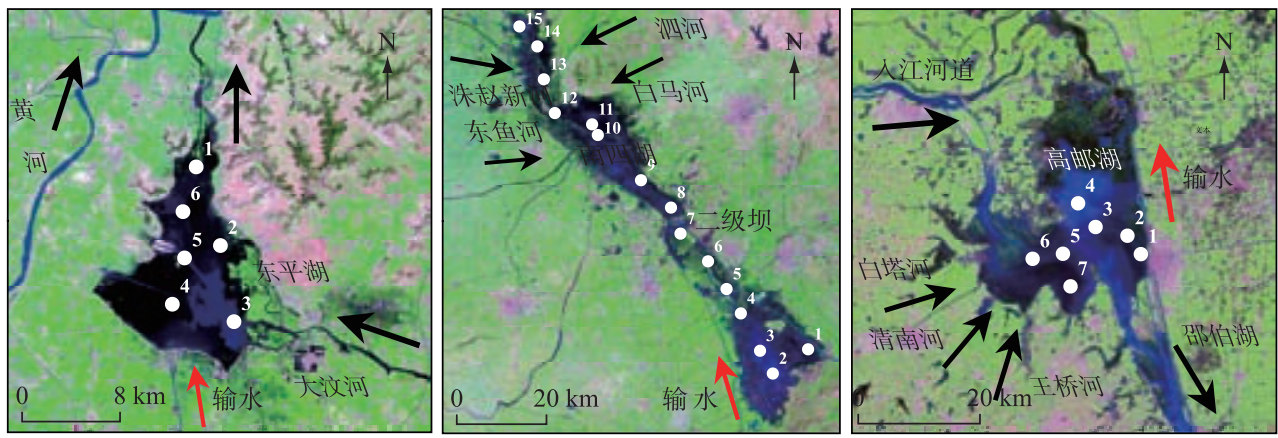

图 1 高邮湖、南四湖及东平湖采样点及流域来水及南水北调路线

Fig. 1 Location of sampling sites in Lake Gaoyou, Lake Nansi and Lake Dongping

\section{3 样品参数的测定}

1.3.1 主要水质参数测定 采样结束当天取 $200 \sim 500 \mathrm{~mL}$ 表层水通过高温灼烧过的 Whatman GF/F 滤膜, 记 录过滤体积, 滤膜用铝箔包好冷冻保存, 测定时先用 $90 \%$ 乙醇在 $80^{\circ} \mathrm{C}$ 提取, 然后采用分光光度法测定 $665 \mathrm{~nm}$ 和 $750 \mathrm{~nm}$ 处的吸光度值以计算出叶绿素 $\mathrm{a}(\mathrm{Chl} . \mathrm{a})$ 浓度, 总氮 $(\mathrm{TN})$ 、总磷 $(\mathrm{TP})$ 浓度的测定均先在 $120^{\circ} \mathrm{C}$ 高温 下消煮 $40 \mathrm{~min}$, 采用 Shimadzu UV-2550PC UV-Vis 测定 ${ }^{[15-16]}$. 利用 Shimadzu 总有机碳分析 ( TOC-L) 在 $680^{\circ} \mathrm{C}$ 高温环境下采用 NPOC 扫吹模式测定 DOC 浓度 ${ }^{[17]}$.

1.3.2 紫外一可见吸收光谱 CDOM 的吸收光谱参数采用 Shimazdu UV-2550 UV-Vis 分光光度计测定. 以 Milli-Q 水为空白对照, 将水样装人 $5 \mathrm{~cm}$ 比色血中, 在 $200 \sim 800 \mathrm{~nm}$ 和间隔 $1 \mathrm{~nm}$ 的设置下测量 CDOM 的吸光 度. 根据公式 (1) 计算对应波长的吸收系数 ${ }^{[18]}$ :

$$
a(\lambda)=2.303 D(\lambda) / r
$$

式中, $a(\lambda)$ 指波长 $\lambda$ 对应 CDOM 吸收系数 $\left(\mathrm{m}^{-1}\right), D(\lambda)$ 指扣除 $700 \mathrm{~nm}$ 处吸光度后在波长 $\lambda$ 的吸光度, $r$ 指 光程路径 $(\mathrm{m})$.

$a(254)$ 表示 CDOM 在 $254 \mathrm{~nm}$ 处的吸收系数, 用于表征 CDOM 丰度 ${ }^{[19]}$. 比紫外吸收系数 SUVA 是 $a$ (254) 与 DOC 浓度的比值, 其值随着 CDOM 的腐殖化程度的增加而增大 ${ }^{[20]}$. CDOM 光谱斜率 $S_{275-295}$ 表示 $275 \sim 295 \mathrm{~nm}$ 波长范围内拟合得到的指数函数的光谱斜率, 能够在一定程度上反映 CDOM 组成, 其值越小, 反映 CDOM 的陆源腐殖酸信号越强. 根据公式 (2) 计算光谱斜率 $S_{275-295}{ }^{[21]}$ :

$$
a(\lambda)=a\left(\lambda_{0}\right) \exp \left[S\left(\lambda_{0}-\lambda\right)\right]
$$

式中, $\lambda_{0}$ 表示参照波长 $440 \mathrm{~nm}, S$ 表示光谱斜率.

1.3.3 三维荧光光谱测定 采用 F-7000 型苂光光度计 (Hitachi 公司) 测定 CDOM 苂光激发一发射光谱矩阵 (excitation-emission matrices, EEMs). 激发光谱范围在 $200 \sim 450 \mathrm{~nm}$, 间隔 $5 \mathrm{~nm}$; 发射光谱范围在 $250 \sim 600$ $\mathrm{nm}$, 间隔 $1 \mathrm{~nm}$. 测得的三维荧光光谱先用超纯水进行拉曼散射校正, 即扣除超纯水 EEMs 光谱, 并以超纯水 EEMs 中 $350 \mathrm{~nm}$ 激发波长和 371 428 nm 发射波长下的苂光强度积分值将所有 EEMs 定标为拉曼单位 (Raman unit,R.U.) ; 再采用 drEEM 工具包裁剪插值的方法进行瑞丽散射校正 ${ }^{[22]}$; 内滤波效应采用相应激发发 射波长处吸光度校正予以消除 ${ }^{[23]}$.

1.3.4 平行因子分析 (PARAFAC) 采用 MATLAB R2015b 的 drEEM 工具箱( ver.0.2.0) 进行平行因子分析, 共抽取 56 个 (东平湖 6 个样点 $\times 2$ 次观测, 南四湖 15 个样点 $\times 2$ 次观测, 高邮湖 7 个样点 $\times 2$ 次观测) EEMs 矩 阵进行运算,每个矩阵对应 251 个发射波长、45 个激发波长. 数据被剖分成 6 个随机子集, 取 3 个子集用于 建模, 另外 3 个用于模型验证, 每个 EEMs 子集均逐步从 3 个组分模型逐步到 6 个组分检验. 本研究结果显 示 3 个组分模型能很好地通过对半检验 (split-half analysis)、随机初始化分析 (random initialization analysis) 及残差分析 (residual analysis). 最后以平行因子分析结果中每个荧光组分的最大苂光强度 $\left(F_{\max }\right)$ 来表征苂 光物质浓度和苂光组分强度 ${ }^{[24]}$. 


\section{4 数据处理}

采用 SPSS 软件对数据进行皮尔逊相关性分析, 数据统计与图表绘制采用 Origin 8.5 软件, 采用 MATLAB R2015b 软件的 drEEM 工具箱进行平行因子分析建模.

\section{2 结果与分析}

\section{1 水文特征}

南四湖、高邮湖和东平湖老湖区 (大汶河经老湖区输人东平湖) 均属于淮河流域. 水文数据表明,淮河流 域 1-4 月和 9-12 月降雨量范围在 16.0 58.2 mm, 而 5-8 月降雨量范围在 89.4 196.9 mm. 东平湖 2018 年 $1-5$ 月蓄水量在 2.6 亿 2.8 亿 $\mathrm{m}^{3} / \mathrm{s}, 6-12$ 月蓄水量在 2.9 亿 5.3 亿 $\mathrm{m}^{3} / \mathrm{s}$. 据此, 本研究将 2018 年 4 月 划为枯水期,2018 年 7 月划为丰水期.

\section{2 主要水质参数特征}

丰水期东平湖 TP、TN 和 Chl. $a$ 浓度显著高于枯水期 $(t$-test, $P<0.01$ 及 $P<0.01)$. 南四湖 TN、TP、Chl. $a$ $(P<0.01)$ 和 DOC $(P<0.05)$ 浓度在丰水期时高于枯水期. 高邮湖 TP、TN 和 Chl.a 浓度在丰水期均显著高于 枯水期 $(t$-test, $P<0.01)$, DOC 浓度无显著差异.

表 1 不同季节之间 3 个湖泊主要水质参数均值差异性 $t$ 检验结果

Tab.1 Mean difference of main water quality parameters of three lakes in different seasons using $t$-test

\begin{tabular}{cccccc}
\hline 湖泊 & 时间 & $\mathrm{TP} /(\mu \mathrm{g} / \mathrm{L})$ & $\mathrm{TN} /(\mathrm{mg} / \mathrm{L})$ & $\mathrm{Chl} . a /(\mu \mathrm{g} / \mathrm{L})$ & $\mathrm{DOC} /(\mathrm{mg} / \mathrm{L})$ \\
\hline 东平湖 & 丰水期 & $61 \pm 31$ & $1.24 \pm 0.22$ & $35.34 \pm 16.51$ & $5.32 \pm 0.37$ \\
& 枯水期 & $47 \pm 8$ & $0.89 \pm 0.05$ & $5.34 \pm 3.24$ & $4.76 \pm 0.71$ \\
& $P$ & $>0.05$ & $<0.01$ & $<0.01$ & $>0.05$ \\
南四湖 & $78 \pm 66$ & $1.27 \pm 0.37$ & $44.99 \pm 29.92$ & $5.59 \pm 0.95$ \\
& 丰水期 & $60 \pm 34$ & $1.11 \pm 0.25$ & $11.67 \pm 5.66$ & $4.58 \pm 0.63$ \\
& 枯水期 & $>0.05$ & $>0.05$ & $<0.01$ & $<0.05$ \\
高邮湖 & $P$ & $93 \pm 30$ & $2.28 \pm 0.36$ & $38.35 \pm 20.74$ & $3.83 \pm 0.40$ \\
& 丰水期 & $45 \pm 6$ & $1.64 \pm 0.38$ & $9.62 \pm 3.74$ & $3.64 \pm 0.26$ \\
& 枯水期 & $<0.01$ & $<0.01$ & $<0.01$ & $>0.05$ \\
\hline
\end{tabular}

\subsection{CDOM 组成来源及丰度的时空分布特征}

从表 2 可以看出, 东平湖的 $S_{275-295}$ 在丰水期显著大于枯水期 $(t$-test, $P<0.05)$, 而 $a(254)$ 和 SUVA 在丰、 枯水期无显著差异. 丰水期东平湖 $a(254)$ 和 SUVA 值在湖中部区域较大, 出湖口和人湖口较低, $S_{275-295}$ 值在 出湖口最大. 枯水期 $a(254)$ 与丰水期相似, $S_{275-295}$ 在人湖口较大, 出湖口最低. SUVA 变化规律与 $S_{275-295}$ 正相

表 2 CDOM 主要特征参数在不同水文条件下的 $t$ 检验结果

Tab.2 Properties of the mean of the three fluorescent components and significance levels of difference between in different hydrological scenarios using $t$-test

\begin{tabular}{ccccc}
\hline 湖泊 & 时间 & $a(254) / \mathrm{m}^{-1}$ & $S_{275-295} / \mu \mathrm{m}^{-1}$ & $\mathrm{SUVA} /(\mathrm{L} /(\mathrm{m} \cdot \mathrm{mg}))$ \\
\hline 东平湖 & 丰水期 & $22.33 \pm 2.32$ & $23.88 \pm 0.70$ & $4.20 \pm 0.42$ \\
& 枯水期 & $23.04 \pm 3.30$ & $22.16 \pm 1.44$ & $4.98 \pm 1.37$ \\
& $P$ & $>0.05$ & $<0.05$ & $>0.05$ \\
南四湖 & 丰水期 & $24.93 \pm 6.09$ & $21.48 \pm 1.07$ & $4.57 \pm 1.22$ \\
& 枯水期 & $21.15 \pm 4.64$ & $21.53 \pm 2.08$ & $4.71 \pm 1.19$ \\
& $P$ & $>0.05$ & $>0.05$ & $>0.05$ \\
高邮湖 & 丰水期 & $22.86 \pm 4.41$ & $18.12 \pm 0.57$ & $7.61 \pm 0.65$ \\
& 枯水期 & $16.61 \pm 0.98$ & $21.50 \pm 0.81$ & $4.70 \pm 0.31$ \\
& $P$ & $<0.01$ & $<0.01$ & $<0.01$ \\
\hline
\end{tabular}


反 (图 2e $\sim f$ ). 南四湖不同水文情景下 $a(254) 、 S_{275-295}$ 和 SUVA 无显著差异, 与东平湖相似. 丰水期 $a(254)$ 在 不同湖区分布较一致, $S_{275-295}$ 在下级湖南部小部分湖区较低, 而 SUVA 值分布与 $S_{275-295}$ 相反, 其值在下级湖泊 较高. 枯水期 $a(254)$ 在上级人湖口最高, $S_{275-295}$ 在上级湖较高, 而在下级出湖口最低, SUVA 与之相反 ( 图 2g 1). 高邮湖在丰水期的吸收系数 $a(254) 、$ SUVA 值均显著高于枯水期 $(t$-test, $P<0.01)$, 而 $S_{275-295}$ 显著 低于枯水期 $(t$-test, $P<0.01)$. 丰水期 $a(254)$ 值在高邮湖西南人湖区域最大, 自西向东呈递减趋势, $S_{275-295}$ 值 在西南区域较低, 而 SUVA 值在该湖西北和西南区域较高. 枯水期 $a(254) 、 S_{275-295}$ 和 SUVA 分布较一致(图 $2 \mathrm{~m} \sim \mathrm{r})$.

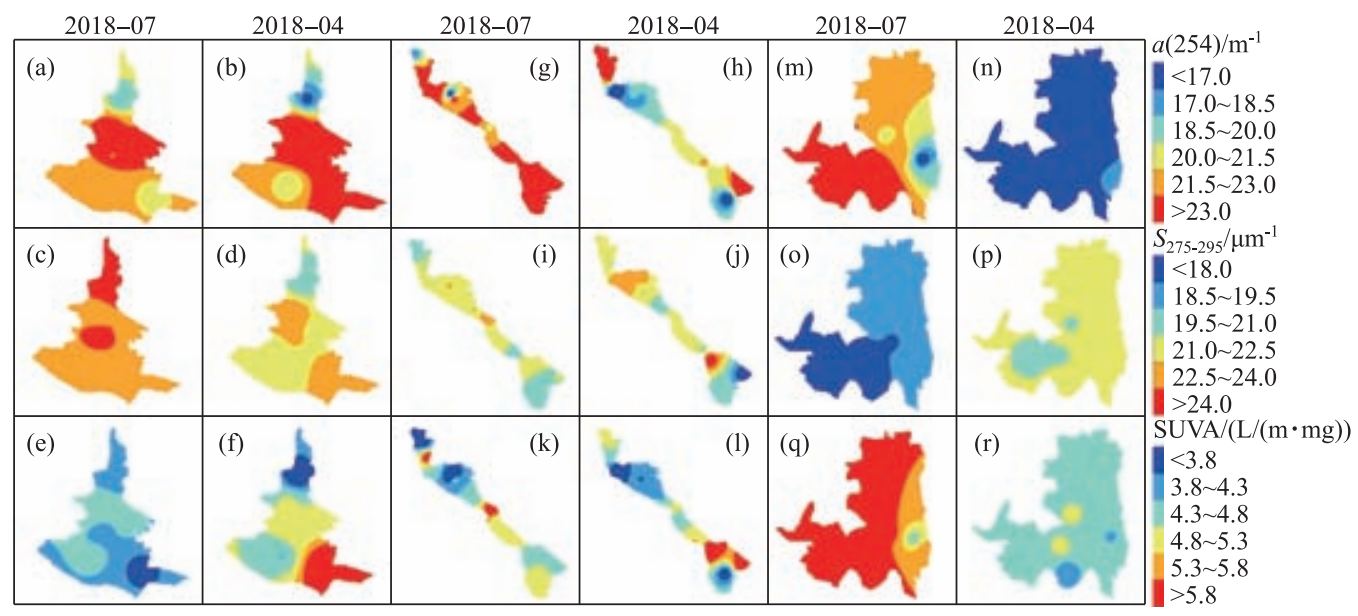

图 2 东平湖丰、南四湖和高邮湖 $a(254) 、 S_{275-295}$ 和 SUVA 时空分布 $((a) \sim(f)$ 为东平湖,$(g) \sim(1)$ 为南四湖,$(m) \sim(r)$ 为高邮湖 $)$

Fig.2 Spatial and temporal distribution of $a(254)$, CDOM spectral slope $S_{275-295}$ and specific ultraviolet absorption at $254 \mathrm{~nm}$ SUVA in Lake Dongping, Lake Nansi and Lake Gaoyou ( (a) -(f) are Lake Dongping, (g)-(l) are Lake Nansi and ( $\mathrm{m})-(\mathrm{r})$ are Lake Gaoyou)

\section{4 荧光组分特征}

2.4.1 苂光组分分析 图 3 是采用 PARAFAC 模型对东平湖、南四湖和高邮湖水样的三维荧光光谱矩阵进行 解析和对半检验得出的 3 个荧光组分. 3 个荧光组分模型可以很好地模拟三维荧光光谱集, 最终确定 3 个组 分分别陆源类腐殖质 C1, 类色氨酸 C2 和类酪氨酸 C3. 组分 C1 荧光光谱类具有陆生植物或土壤有机物质光 谱特征, 发射和激发波长分别为 $430 、 250 \mathrm{~nm}^{[25]}$. 组分 $\mathrm{C} 2$ 苂光光谱通常与藻源、生活废水排放有关, 为类蛋 白质中的类色氨酸荧光物质, 有 1 个发射波长在 $350 \mathrm{~nm}$ 处, 2 个激发波长, 即 225 和 $275 \mathrm{~nm}$ 处 ${ }^{[26]}$. 组分 C3 一般是藻源, 或其他苂光组分在水体中经光化学、微生物矿化等作用的产物, 其荧光光谱光谱 $(275 \mathrm{~nm} / 310$ $\mathrm{nm}$ ) 代表类蛋白质中的酪氨酸苂光物质 ${ }^{[27]}$.

2.4.2 苂光组分时空分布特征 由表 3 可知, 丰水期东平湖 3 个组分苂光强度显著低于枯水期 $(t$-test, $P<$ 0.01 ), 而且丰水期 3 个组分空间分布较一致 (图 4a f). 与东平湖相同的是, 南四湖组分 C2、C3 苂光强度在 丰水期均显著低于枯水期 $(t$-test,$P<0.01)$, 且组分 C2 苂光强度在枯水期最高. 不同水文情境下, 组分 C2、 C3 苂光强度均高于组分 $\mathrm{C} 1$. 图 $4 \mathrm{~g} \sim \mathrm{j}$ 表明从上级湖区至下级湖区方向, 组分 C2、C3 有递增趋势, 而组分 $\mathrm{C} 1$ 在不同水文情景下空间分布相似, 且在出湖口较低. 与东平湖、南四湖相反, 高邮湖组分 C1 苂光强度在丰、 枯水期高于两种类蛋白质物质, 且组分 C1、C2 苂光强度显著高于枯水期 ( $t$-test, $P<0.01$ ). 图 4m、q 表明丰 水期高邮湖西北湖区组分 C1、C3 苂光强度均高于其他区域. 枯水期 3 个组分在高邮湖空间分布较均匀 (图 $4 \mathrm{n}, \mathrm{p}, \mathrm{r})$. 

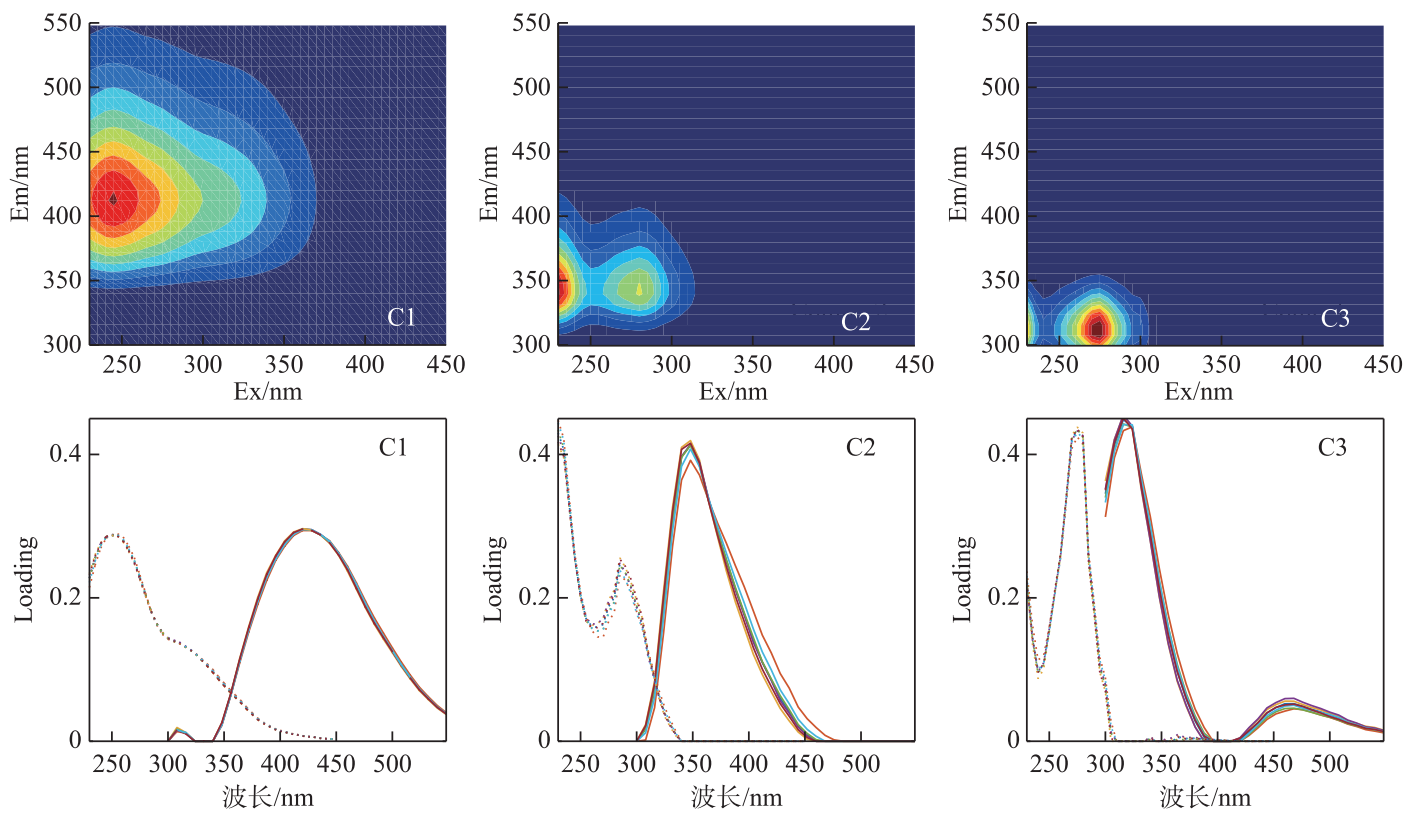

图 3 平行因子分析得到的 3 个苂光组分苂光光谱和对半检验结果

Fig.3 Fluorescent spectra of the three PARAFAC components

( The three-component-model was well-validated using split-half validation procedure)

表 33 个组分苂光强度在不同水文条件下的均值差异显著性水平 $t$ 检验结果

Tab.3 Properties of the mean of the three fluorescent components and significance levels of difference in different hydrological scenarios using $t$-test

\begin{tabular}{ccccc}
\hline 湖泊 & 时间 & $\mathrm{C} 1$ & $\mathrm{C} 2$ & $\mathrm{C} 3$ \\
\hline 东平湖 & 丰水期 & $0.64 \pm 0.06$ & $0.70 \pm 0.03$ & $0.39 \pm 0.06$ \\
& 枯水期 & $0.72 \pm 0.06$ & $1.12 \pm 0.18$ & $0.68 \pm 0.18$ \\
& $P$ & $<0.05$ & $<0.01$ & $<0.01$ \\
南四湖 & 丰水期 & $0.65 \pm 0.14$ & $0.68 \pm 0.12$ & $0.57 \pm 0.16$ \\
& 枯水期 & $0.67 \pm 0.15$ & $1.19 \pm 0.55$ & $0.88 \pm 0.34$ \\
& $P$ & $>0.05$ & $<0.01$ & $<0.01$ \\
高邮湖 & 丰水期 & $0.85 \pm 0.18$ & $0.38 \pm 0.06$ & $0.31 \pm 0.05$ \\
& 枯水期 & $0.56 \pm 0.03$ & $0.49 \pm 0.05$ & $0.35 \pm 0.03$ \\
& $P$ & $<0.01$ & $<0.01$ & $>0.05$ \\
\hline
\end{tabular}

\section{5 苂光组分与主要水质参数相关性}

东平湖和南四湖的 CDOM 吸收、苂光光谱以及水质参数在不同水文情景下和空间分布存在相似的规 律, 高邮湖与这 2 个湖泊存在明显的差异, 因此将东平湖、南四湖数据合并进行相关性分析. 由图 5 、图 6 可 以看出, TP、TN 和 Chl. $a$ 与高邮湖中类腐殖质菼光强度均有显著正相关性, 类蛋白与 Chl. $a$ 浓度呈负相关. 东平湖、南四湖类腐殖质苂光强度与 $\mathrm{TP}$ 有较好的正相关性, 类色氨酸苂光强度与 $\mathrm{TN}$ 呈负相关, 两类蛋白组 分与 Chl. $a$ 、DOC 也均呈负相关. 高邮湖的类腐殖质荧光强度与 $a(254)$ 、SUVA 呈显著正相关, 而南四湖和东 平湖类腐殖质荧光强度与 $a(254)$ 相关性较好. 


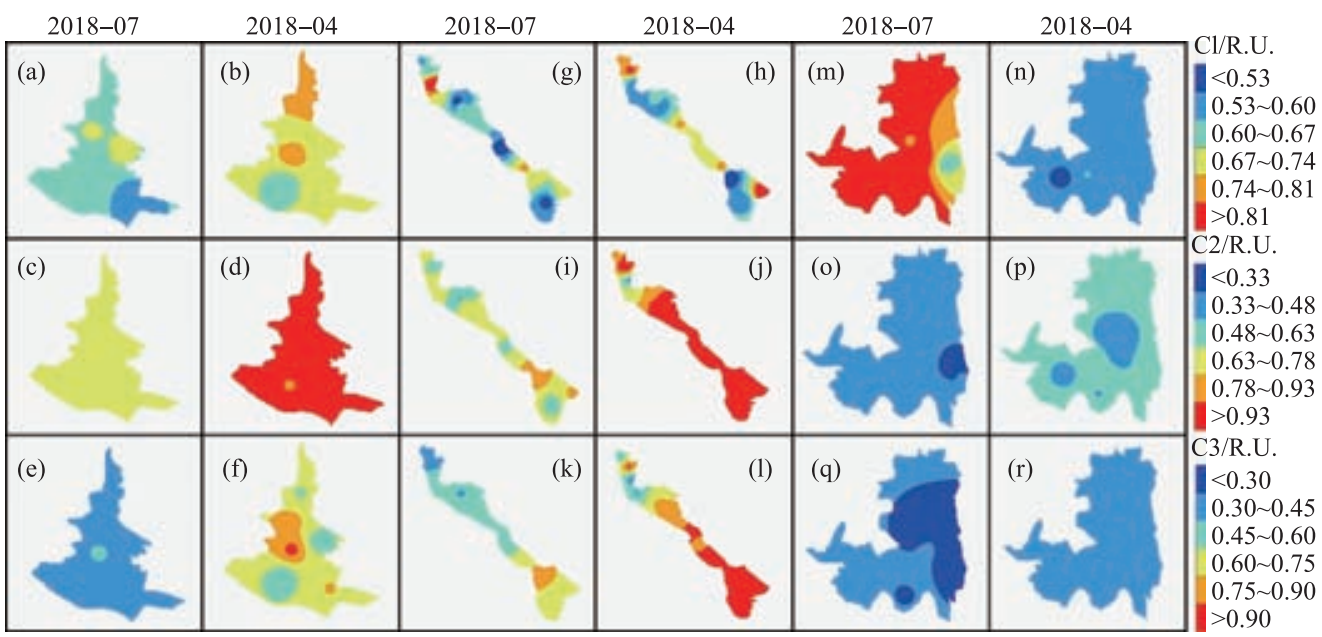

图 4 东平湖、南四湖和高邮湖 3 种组分荧光强度时空分布 $((a) \sim(f)$ 为东平湖,$(g) \sim(1)$ 为南四湖,$(m) \sim(r)$ 为高邮湖 $)$

Fig.4 Spatial and temporal distribution of fluorescence intensity of three components in Lake Dongping, Lake Nansi and Lake Gaoyou ( (a)-(f) are Lake Dongping, (g)-(l) are Lake Nansi and (m)-(r) are Lake Gaoyou)

\section{3 讨论}

\section{1 水质参数与 $\mathrm{CDOM}$ 的来源组成的关系}

CDOM 苂光光谱测定能在一定程度上反映 DOC 的来源, 与李奕洁等 ${ }^{[28]}$ 的研究相同, 不同水文情境下高 邮湖 DOC 浓度与类腐殖质苂光强度呈显著正相关, 与两个蛋白组分苂光强度相关性较差, 这意味着类腐殖 质是高邮湖 DOC 主要组成部分. 这是由于高邮湖位于洪泽湖下游, 为典型过水型湖泊, 水力滞留时间短, 该 湖 CDOM 和 DOC 主要来自上游淮河流域降水径流等冲刷的土壤有机质输人. 然而南四湖和东平湖类腐殖 质与 DOC 相关性较差, 两类蛋白苂光强度与 DOC 呈负相关, 而 DOC 在枯水期较低, 表明两湖泊在枯水期受 流域内工农业污染以及点源污染的影响较大 ${ }^{[29]}$. 江俊武等 ${ }^{[30]}$ 研究结果显示 Chl. $a$ 浓度较高, 水体中类蛋白 苂光强度也较高, 然而也有研究者发现二者并无显著相关性 ${ }^{[31-32]}$, 本研究 3 个湖泊中 Chl. $a$ 浓度与两种类蛋 白物质有负相关性, 3 个湖泊类蛋白组分荧光强度均高于丰水期. Mayer 等 ${ }^{[33]}$ 发现缅因州河口部分点位 CDOM 样品也有该现象, 这意味着 3 个湖泊中两种类蛋白物质, 即类色氨酸和类酪氨酸并非主要来自浮游生 物死亡降解. 有研究表明城市生活污水通常携带强烈的类色氨酸及类酪氨酸等类蛋白苂光信号 ${ }^{[34-35]}$, 意味 着 3 个湖泊两种类蛋白物质在春季 (枯水期) 较高可能与湖泊周边流域人类生产生活废水排人相关. 而高邮 湖类腐殖质与 Chl. $a$ 浓度有较好的正相关性, 表明了高邮湖中浮游植物的生长伴随着较高的陆源类腐殖质 输人, 丰水期 Chl. $a$ 浓度、 $a(254)$ 和类腐殖质苂光强度均高于枯水期可以进一步说明. 同时, 高邮湖的类腐 殖质菼光强度与 TN、TP 有显著正相关也表明了陆源腐殖质的输人与氮磷元素的迁移转化密切相关, 这与王 书航等 ${ }^{[36]}$ 的研究一致.

\section{2 主要入湖河流对湖泊 CDOM 来源与组成的影响}

一般情况下,内陆水体中 CDOM 主要来自陆源输人,并且陆源输人会携带大量的大分子有机物质进人 水体 ${ }^{[37]}$. 本研究结果表明, 高邮湖 CDOM 丰度在河流人湖区域较高, 自西向东有下降的趋势, $S_{275-295}$ 值为相 反的变化规律, 亦即 $S_{275-29}$ 值自河口区向敞水区逐渐增大, 这意味着陆源土壤有机质输人信号也逐渐减弱, 人湖河流输人为高邮湖 CDOM 的主要贡献源, 且 CDOM 向敞水区输移过程中一方面逐渐被湖水稀释, 另一 方面, 微生物活动及光降解作用亦导致高邮湖 CDOM 逐渐被降解 ${ }^{[38]}$. 类腐殖质和类酪氨酸苂光强度逐渐降 低进一步印证上述结论. 南四湖人湖河流主要经上级湖泊汇人, 枯水期南四湖下级湖泊 CDOM 丰度高于上 

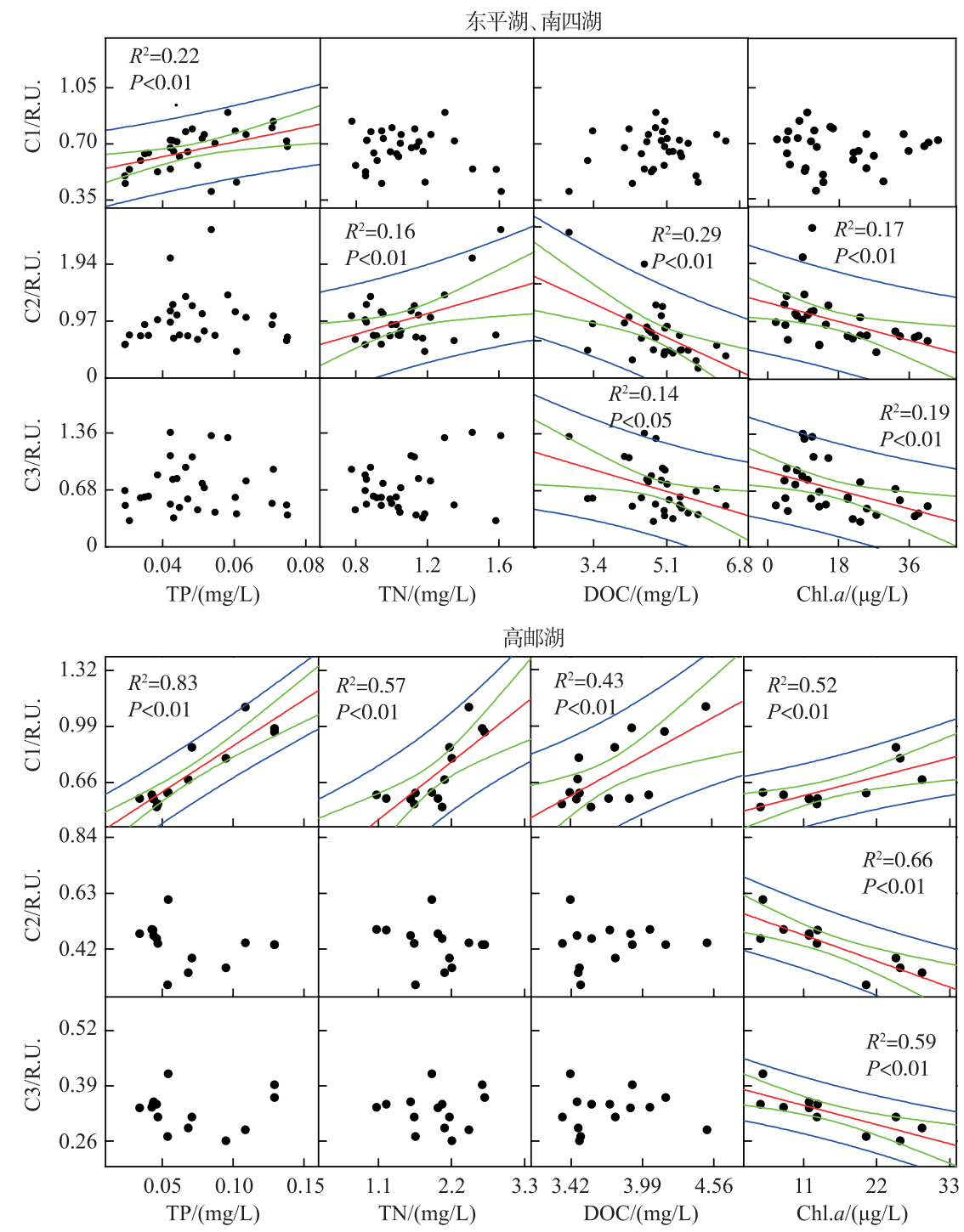

图 53 组苂光组分与主要水质参数的相关性分析

Fig.5 Correlations between the three PARAFAC components and main water quality parameters

级湖泊. 并且不同水文情景下, 类蛋白组分苂光强度和 $a(254)$ 在下级湖区较高, 表明人湖河流对上级湖泊 CDOM 的影响较小, 然而下级湖泊出现高值主要是受到山东本庄、济宁、菏泽城市废水的影响, 加上冬季来 水量较低,稀释作用不明显, 类蛋白组分在湖泊中较高 ${ }^{[39]}$. 东平湖 $a(254)$ 值在南部和湖中心区域较大, 表明 $\mathrm{CDOM}$ 丰度也受人湖河流的影响, 这与吕伟伟等 ${ }^{[40]}$ 的研究结果一致.

\section{3 不同水文情景对湖泊 CDOM 来源与组成的影响}

高邮湖在丰水期其类腐殖质苂光强度较高, 自西向东有递减趋势, 这与 $a(254)$ 的分布趋势一致, 表明高 邮湖 CDOM 在丰水期受陆源输人的影响较大, 类腐殖质与 $a(254) 、 S_{275-295}$ 、SUVA 有较好的相关性能进一步 说明该现象. 东平湖和南四湖 3 个组分苂光强度在枯水期均高于丰水期,但不同水文情景下 3 个苂光组分 与 $a(254) 、 S_{275-295}$ 和 SUVA 相关性较差, 相关分析结果也表明浮游植物不是 CDOM 的主要来源, 根据姚昕 等 ${ }^{[1]}$ 的研究, 表明这与东平湖沉积物再悬浮以及外源输人有关. 东平湖丰水期 TP、TN 和 Chl. $a$ 浓度均高于 

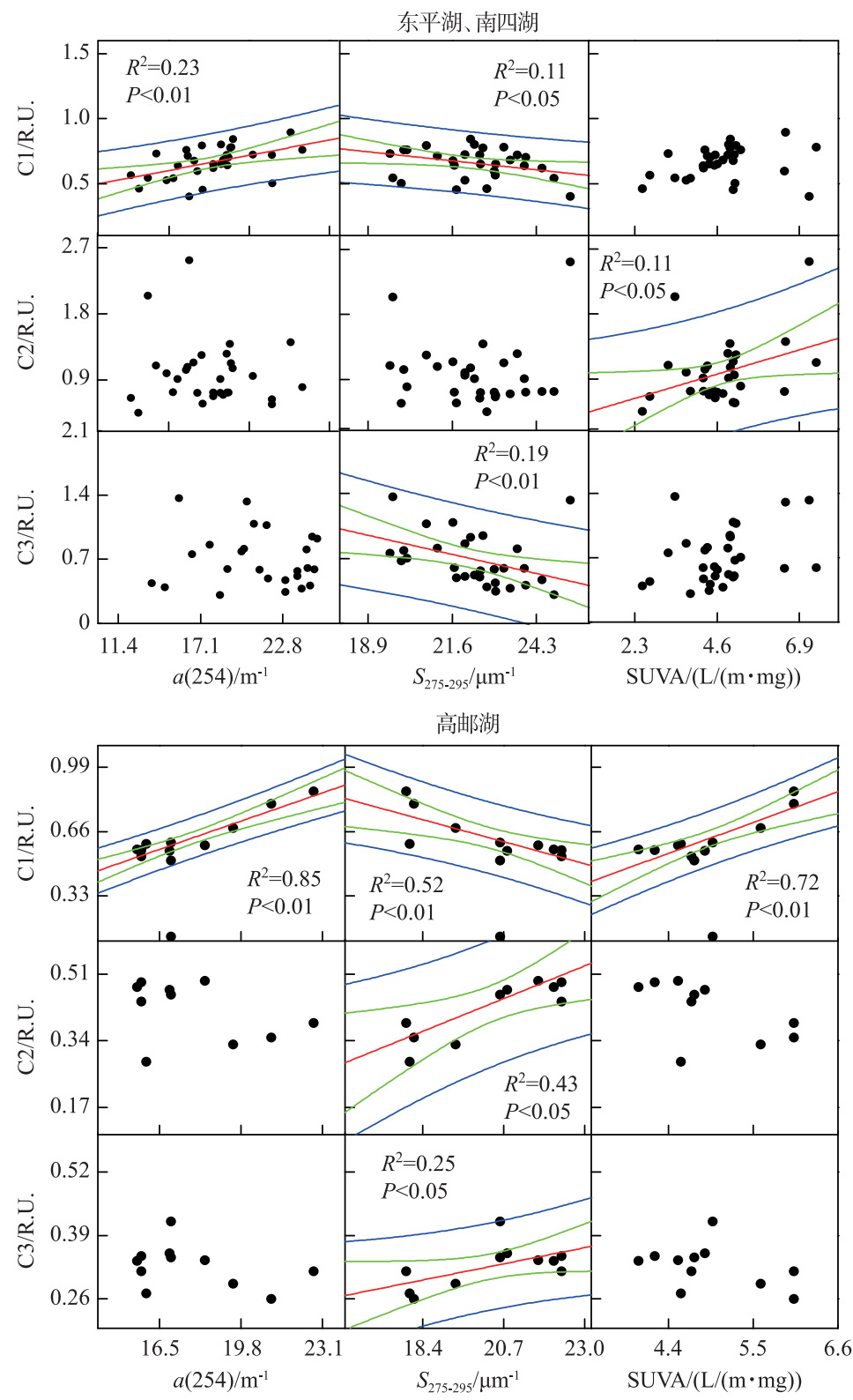

图 63 组苂光组分与荧光特征参数的相关性分析

Fig.6 Correlations between the three PARAFAC components and fluorescence characteristic parameter

枯水期,这与该湖泊处于中富一富营养化相关, 张菊等 ${ }^{[41]}$ 的研究也发现东平湖夏、秋季节会有一部分草和藻 出现死亡现象,特别是菹草的腐烂降解会对 TN 有巨大的贡献. 整体来看, 南四湖枯水期上级湖北部区域 CDOM 苂光强度较低, 下级湖区接纳的东线调水对湖泊自净能力有一定的提升作用,因此沿调水方向 CDOM 苂光强度减弱,这与赵世新等 ${ }^{[42]}$ 对南四湖水质状况的研究结果相似. 湖泊的营养状况、水生植物多样性以 及底泥沉积物的释放等过程对 CDOM 的来源组成特征影响因素,因此仍需要进一步的研究 ${ }^{[43]}$. 


\section{4 结论}

1) 高邮湖丰水期类腐殖质是其 CDOM 库的主要贡献者. 枯水期东平湖和南四湖下级湖泊类蛋白组分 受外源人类活动污染源排放的影响较大.

2) 不同水文情景对高邮湖 CDOM 苂光特征的影响最明显, 丰水期 CDOM 以陆源输人为主. 不同水文情 景对东平湖和南四湖 CDOM 组成结构影响较小, 类蛋白荧光强度在枯水期较高, 藻类降解的作用贡献较小.

3) 高邮湖的类腐殖质荧光特征能较好地反演 DOC, 还能在一定程度上预测 TN 、TP 和 Chl. $a$ 水质参数的 变化情况. 而南四湖、东平湖 CDOM 苂光特征与主要水质参数相关性较差.

致谢: 感谢邹伟、徐轩、任浩宇、刘氷、李娜、张成英及邢晓晟等同志在野外与室内实验过程中给予的帮助.

\section{5 参考文献}

[ 1 ] Yang Y, Yin L, Zhang Q. Quantity versus quality in China's South-to-North Water Diversion Project; a system dynamics analysis. Water, 2015, 7(5): 2142-2160.

[ 2 ] Zeng Q, Qin L, Li X. The potential impact of an inter-basin water transfer project on nutrients ( nitrogen and phosphorous) and chlorophyll a of the receiving water system. Science of the Total Environment, 2015, 536: 675-686.

[ 3 ] Li S, Guo W, Yin Y et al. Environmental changes inferred from lacustrine sediments and historical literature: A record from Gaoyou Lake, eastern China. Quaternary International, 2015, 380/381 : 350-357.

[ 4 ] Wu ZH, Zhang K, Jin LR et al. Analysis of spatial distribution of water quality and assessment of water quality improvement in Nansi Lake. Water Resources Protection, 2012, 28(6): 1-7. [武周虎, 张可, 金玲仁等. 南四湖水质空间分布 特征分析与改善效果评估. 水资源保护, 2012, 28(6) : 1-7.]

[ 5 ] Luo WL, Tian J, Zhang J et al. Characterization of nutrient pollution of Dongping Lake winter water and its quality assessment. Transaction of Oceanology and Limnology, 2016, (2) : 8-16. [罗文否, 田娟, 张菊等. 东平湖冬季水体营养盐 污染特征及水质评价. 海洋湖沼通报, 2016, (2) : 8-16.]

[ 6 ] Song YJ, Liu LH, Shi ZY et al. Environment impact of long distance water transfer on the water conveyance line and receiving water body. South-to-North Water Diversion and Water Science \& Technology, 2012, 10(3) : 98-102. [宋亚净, 刘 立华, 石兆英等. 长距离调水对沿线及受纳水体水环境的影响. 南水北调与水利科技, 2012, 10(3): 98-102.]

[ 7 ] Guo P, Ren J. Variation trend analysis of water quality along the eastern route of south-to-north water diversion project. South-to-North Water Diversion and Water Science \& Technology, 2014, 12(1): 59-64. [郭鹏, 任静. 南水北调东线一 期工程沿线历年水质变化分析. 南水北调与水利科技, 2014, 12(1): 59-64.]

[ 8 ] Wang M, Chen Y. Generation and characterization of DOM in wastewater treatment processes. Chemosphere, 2018, 201: 96-109.

[ 9 ] Song K, Li L, Tedesco L et al. Spectral characterization of colored dissolved organic matter for productive inland waters and its source analysis. Chinese Geographical Science, 2015, 25(3) : 295-308.

[10] Su W, Jiang GJ, Kong FX et al. Characteristics of chromophoric dissolved organic matter in inland waters. Resources and Environment in the Yangtze Basin, 2015, 24(1): 114-121. [苏文, 姜广甲, 孔繁翔等. 内陆水体有色溶解有机物的 变化特征. 长江流域资源与环境, 2015, 24(1)：114-121.]

[11] Yao X, Sun JL, Dong J et al. Absorption characteristics and environment significance of dissolved organic matter lake Dongping. Spectroscopy and Spectral Analysis, 2016, 36(10): 3232-3236. [姚昕, 孙将凌, 董杰等. 东平湖 CDOM 的 光谱吸收特征及环境指示意义. 光谱学与光谱分析, 2016, 36(10) : 3232-3236.]

[12] Shang Y, Song K, Jacinthe PA et al. Characterization of CDOM in reservoirs and its linkage to trophic status assessment across China using spectroscopic analysis. Journal of Hydrology, 2019,576:1-11.

[13] Hu B, Wang P, Qian J et al. Characteristics, sources, and photobleaching of chromophoric dissolved organic matter ( CDOM) in large and shallow Hongze Lake, China. Journal of Great Lakes Research, 2017, 43: 1165-1172.

[14] Coch C, Juhls B, Lamoureux SF et al. Characterizing organic matter composition in small Low and High Arctic catchments using terrestrial colored dissolved organic matter (CDOM). Biogeosciences Discussion, 2019. DOI: org/10.5194/bg2019-9.

[15] Zhu M, Zhu G, Zhao LL. Influence of algal bloom degradation on nutrient release at the sediment-water interface in Lake 
Taihu, China. Environmental Science and Pollution Research International, 2013, 20(3) : 1803-1811.

[16] Zhu M, Zhu G, Li W et al. Estimation of the algal-available phosphorus pool in sediments of a large, shallow eutrophic lake (Taihu, China) using profiled SMT fractional analysis. Environmental Pollution, 2013, 173: 216-223.

[17] Wang Y, Zhang D, Shen Z et al. Characterization and spatial distribution variability of chromophoric dissolved organic matter( CDOM) in the Yangtze Estuary. Chemosphere, 2014, 95(1) : 353-362.

[18] Kowalczuk P, StońEgiert J, Cooper WJ et al. Characterization of chromophoric dissolved organic matter ( CDOM) in the Baltic Sea by excitation emission matrix fluorescence spectroscopy. Marine Chemistry, 2005, 96(3) : 273-292.

[19] Andrew AA, Del Vecchio R, Subramaniam A et al. Chromophoric dissolved organic matter ( CDOM) in the Equatorial Atlantic Ocean: Optical properties and their relation to CDOM structure and source. Marine Chemistry, 2013, 148: 33-43.

[20] Kothawala DN, Stedmon CA, Müller RA et al. Controls of dissolved organic matter quality : evidence from a large-scale boreal lake survey. Global Change Biology, 2014, 20(4): 1101-1114.

[21] Ma HP, Zhang J, Gao XC et al. Optical properties of the colored dissolved organic matter in the East China Sea in autumn. Marine Environment Science, 2014, 33(6): 876-883. [马海平, 张婧, 高先池等. 秋季东海有色溶解有机物 ( CDOM) 的光学特性. 海洋环境科学, $2014, \mathbf{3 3}(6)$ : 876-883.]

[22] Murphy KR, Stedmon CA, Graeber D et al. Fluorescence spectroscopy and multi-way techniques. PARAFAC. Analytical Methods, 2013, 23(5) : 6557-6566.

[23] O'Donnell JA, Aiken GR, Butler KD et al. DOM composition and transformation in boreal forest soils: The effects of temperature and organic-horizon decomposition state. Journal of Geophysical Research: Biogeosciences, 2016, 121 (10): 2727-2744.

[24] Stedmon CA, Bro R. Characterizing dissolved organic matter fluorescence with parallel factor analysis: A tutorial. Limnology and Oceanography: Methods, 2008, 6(11) : 572-579.

[25] Stedmon CA, Markager S. Resolving the variability in dissolved organic matter fluorescence in a temperate estuary and its catchment using PARAFAC analysis. Limnology \& Oceanography, 2005, 50(2) : 686-697.

[26] Murphy KR, Ruiz GM, Dunsmuir WTM et al. Optimized parameters for fluorescence-based verification of ballast water exchange by ships. Environmental \& Technology, 2006, 40(7) : 2357-2362.

[27] Cory RM, McKnight DM. Fluorescence spectroscopy reveals ubiquitous presence of oxidized and reduced quinones in dissolved organic matter. Environmental Science \& Technology, 2005, 39(21) : 8142-8149.

[28] Li YJ, Wang GS, Hu SZ et al. Optical characterization, distribution and sources of chromophoric dissolved organic material ( CDOM) in the Changjiang River estuary in July 2014. Oceanologia et Limnologia Sinica, 2015, 46(3) : 670-678. [李 奕洁, 宋贵生, 胡素征等. 2014 年夏季长江口有色溶解有机物 (CDOM) 的分布、光学特性及其来源探究. 海洋与湖 沼, 2015, 46(3) : 670-678.]

[29] Wu ZH, Mu JB, Xie G et al. Analysis of water environmental quality variation trends in Nansi Lake and its joined rivers. Research of Environmental Sciences, 2010, 23(9): 1167-1173. [武周虎, 慕金波, 谢刚等. 南四湖及人出湖河流水环 境质量变化趋势分析. 环境科学研究, 2010, 23(9): 1167-1173.]

[30] Jiang JW, Li SD, Shen YY et al. Spatial differences of optical properties of CDOM and their source apportionment in Taihu Lake in summer. Research of Environmental Sciences, 2017, 30(7): 1020-1030. [江俊武, 李帅东, 沈胤胤等. 夏季太 湖 CDOM 光学特性空间差异及其来源解析. 环境科学研究, 2017, 30(7) : 1020-1030. ]

[31] Chen J, Gu BH, Leboeuf EJ et al. Spectroscopic characterization of the structural and functional properties of natural organic matter fractions. Chemosphere, 2002, 48(1) : 59-68.

[32] Song XN, Yu T, Zhang Y et al. Distribution characterization and source analysis of dissolved organic matters in Taihu Lake using three dimensional fluorescence excitation-emission matrix. Acta Scientiae Circumstantiae, 2010, 30 (11): 23212331. [宋晓娜, 于涛, 张远等. 利用三维苂光技术分析太湖水体溶解性有机质的分布特征及来源. 环境科学学 报, 2010, 30(11): 2321-2331.]

[33] Mayer LM, Schick LL, Iii TCL. Dissolved protein fluorescence in two maine estuaries. Marine Chemistry, 1999, 64(3): 171-179.

[34] Stedmon CA, Seredyńska-Sobecka B, Boe-Hansen R et al. A potential approach for monitoring drinking water quality from groundwater systems using organic matter fluorescence as an early warning for contamination events. Water Research, 2011, 45(18): 6030-6038. 
[35] Zhou Y, Jeppesen E, Zhang Y et al. Dissolved organic matter fluorescence at wavelength 275/342 nm as a key indicator for detection of point-source contamination in a large Chinese drinking water lake. Chemosphere, 2016, 144: 503-509.

[36] Wang SH, Wang WW, Jiang X et al. Distribution of chromophoric dissolved organic matter in Lihu Lake using excitationemission matrix fluorescence and parallel factor analysis. China Environmental Science, 2016, 36(2) : 517-524. [王书 航, 王雯雯, 姜霞等. 基于三维苂光光谱一平行因子分析技术的蟙湖 CDOM 分布特征. 中国环境科学, 2016, 36 (2) : 517-524.]

[37] Zhou YQ, Zhou J, Jeppesen E et al. Will enhanced turbulence in inland waters result in elevated production of autochthonous dissolved organic matter. Science of the Total Environment, 2016, 543(Pt A) : 405-415.

[38] Kolic PE, Roy ED, White JR et al. Spectroscopic measurements of estuarine dissolved organic matter dynamics during a large-scale Mississippi River flood diversion. Science of the Total Environment, 2014, 485/486: 518-527.

[39] Wang W, Yang C, Dong C et al. Design and implementation of risk assessment model for hazard installations based on AHP-FCE method: A case study of Nansi Lake Basin. Ecological Informatics, 2016, 36: 162-171.

[40] Lv WW, Yao X, Zhang BH. Correlations between fluorescence characteristics of chromophoric dissolved organic matter and nutrients in Dawen River and Dongping Lake. Ecology and Environmental Sciences, 2018, 27(3) : 565-572. [吕伟伟, 姚 昕, 张保华. 大汶河-东平湖 CDOM 的苂光特征及与营养物质的耦合关系. 生态环境学报, 2018, 27 (3): 565-572.]

[41] Zhang J, Deng HG, Chen SY et al. Eco-environment health risk assessment of Dongping Lake water-resources. Journal of Safety and Environment, 2011, 11(6): 111-115. [张菊, 邓焕广, 陈诗越等. 东平湖水源地水环境健康风险初步评 价. 安全与环境学报, 2011, 11(6): 111-115.]

[42] Zhao SX, Zhang C, Gao XP et al. The impact of the operation of Eastern Route Project of the South-to-North Water Diversion Project on water quality in Lake Nansi. J Lake Sci, 2012, 24(6) : 923-931. DOI: 10.18307/2012.0616. [赵世新, 张晨, 高学平等. 南水北调东线调度对南四湖水质的影响. 湖泊科学, 2012, 24(6) : 923-931.]

[43] Zhang Q. The South-to-North Water Transfer Project of China: Environmental implications and monitoring strategy1. Journal of the American Water Resources Association, 2009, 45(5) : 1238-1247. 